\title{
LOW-COST DATA ACQUISITION UNIT FOR FLIGHT TESTS
}

\author{
Błażej Morawski ${ }^{1}$, \\ Dominik Głowacki ${ }^{1}$ • ORCID 0000-0003-2344-3085, \\ Anna Głowacka² • ORCID 0000-0002-2758-5753. \\ ${ }^{1}$ Warsaw University of Technology, Institute of Aeronautics and Applied Mechanics, \\ plac Politechniki 1, 00-661 Warsaw, Poland \\ ${ }^{2}$ Warsaw University of Technology, Institute of Machine Design Fundamentals, \\ plac Politechniki 1, 00-661 Warsaw, Poland \\ blazej.morawski@gmail.com,dglowacki@meil.pw.edu.pl, \\ anna.glowacka@pw.edu.pl
}

\begin{abstract}
The purpose of this paper is to present the design of a data recorder for flight tests of a full-scale aircraft and an UAV. The recorder is built based on the Arduino microprocessor platform and LabVIEW development environment. The data recorder will be used mainly for helicopter flight tests.
\end{abstract}

Keywords: helicopter flight test, LabVIEW, Arduino.

\section{INTRODUCTION}

Each new or modified type of aircraft requires ground and flight testing to prove compliance with appropriate design regulations (e.g. FAR regulations issued by FAA or CS issued by EASA). Most flight tests must be documented by registering the appropriate flight parameters such as acceleration, angular velocity, magnetic course, pressure, GPS positions, temperature, vibrations, as well as strain and loads, which are the most difficult parameters to measure, especially on a full-scale aircraft.

To register the above mentioned parameters specially designed equipment is used. Dedicated equipment for flight tests measurements is very expensive, especially for small or new aircraft producers.

In the era of widely developed and available microcontrollers and PCBs it is possible, however, to record flight data using low-cost methods with platforms like Arduino, myRIO, RaspberryPi, Nucleo etc. For these platforms a number of small sensors with good accuracy are presently available which were not available several years ago.

In our paper, we discuss the use of Arduino platforms with widely available and cheap sensors and LabVIEW development environment. 

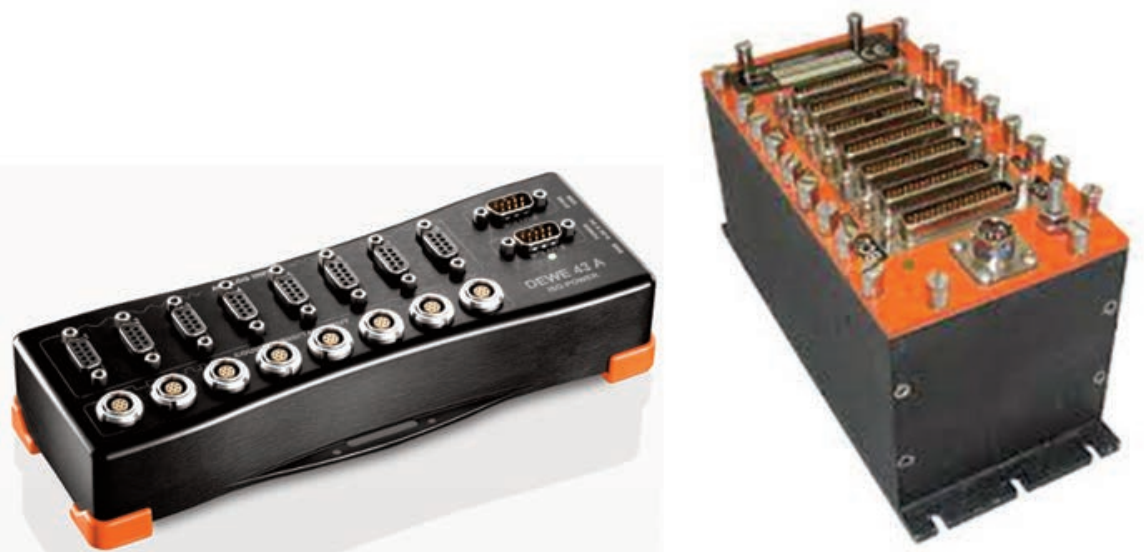

\section{Figure 1. Data acquisition units for flight tests designed by DEWESoft and Curtis Wright (price at the level of 30,000 USD).}

Arduino is an open source microprocessor platform based on the 8-bit AVR microcontroller (exception is the Arduino Due based on the 32-bit ARM Cortex core). Arduino is intended for home, hobby and industry (Industruino version) use. This microcontroller was designed to work together with different sensor types, electrical engine, displays etc.

One of the biggest advantages of this platform is world-wide support, a large number of users around the world (e.g. the international official forum) and the availability of education materials. Arduino has also a large number of extension sets (Arduino Shield).

Arduino can be a stand-alone system or cooperate with a PC using UART or Ethernet protocol (using the Arduino Shield it is possible to extend the types of protocols).

There are a lot of Arduino versions on the market such as Arduino Uno, Mega, Leonardo etc.
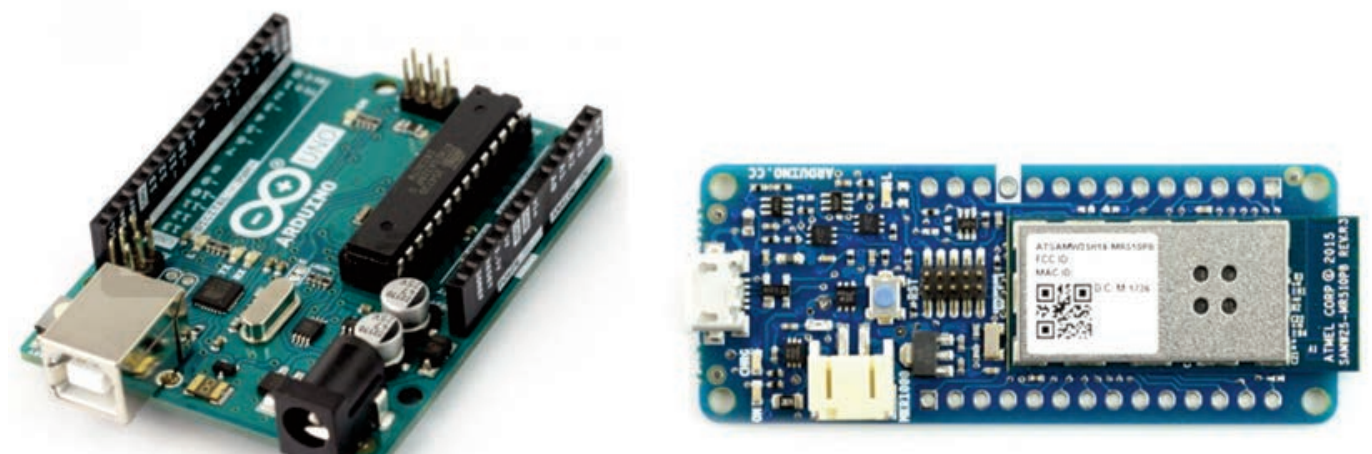

Figure 2. Arduino Uno and Arduino MKR 1000 WiFi used in the project.

For different types of measurements it is possible to use different sensors. Examples of sensors with basic description are listed below:

- Internal Measurement Unit (IMU) SparkFun LSM9DS1 - contains 3-axis accelerometers, 3-axis gyroscopes and a magnetometer. 
Table 1. LSM9DS1 Basic data.

\begin{tabular}{|c|c|}
\hline Parameter & Value \\
\hline Gyroscopes range & $\pm 245,500$ and $2000[\mathrm{deg} / \mathrm{s}]$ \\
\hline Gyroscope sample rate & $952[\mathrm{~Hz}]$ \\
\hline Accelerometers range & $\pm 4,8,12$ and $16[\mathrm{~g}]$ \\
\hline Accelerometer sample rate & $952[\mathrm{~Hz}]$ \\
\hline Magnetometer range & $\pm 4,8,12,16[\mathrm{Gs}]$ \\
\hline Digital resolution & 16 bit \\
\hline Communication & $\mathrm{I}^{2} \mathrm{C}$ and SPI \\
\hline Mass & $1,8[\mathrm{~g}]$ \\
\hline
\end{tabular}

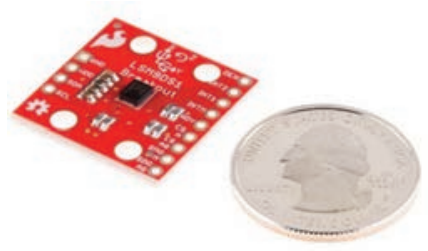

Figure 3. LSM9DS1 IMU.

- Adafruit ADXL345 - is a 3-axis accelerometer which can be used during flight for construction vibration or aircraft loads measurement and it can also be used for flutter investigations.

Table 2. ADXL345 Basic data.

\begin{tabular}{|c|c|}
\hline Parameter & Value \\
\hline Accelerometers range & $\pm 2,4,8$ and $16[\mathrm{~g}]$ \\
\hline Accelerometer sample rate & $3200[\mathrm{~Hz}]$ \\
\hline Digital resolution & 16 bit \\
\hline Communication & $\mathrm{I}^{2} \mathrm{C}$ and SPI \\
\hline Mass & $1,7[\mathrm{~g}]$ \\
\hline
\end{tabular}

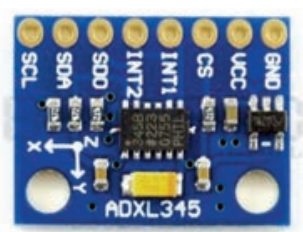

Figure 4. ADXL345 Accelerometer.

- Digilenbt PMOD DPG1 - differential pressure gauge sensor. It can be used for airspeed indicator calibration. 
Table 3. PMOD DPG1 Basic data.

\begin{tabular}{|c|c|}
\hline Parameter & Value \\
\hline Differential pressure range & $0-10[\mathrm{kPa}]$ \\
\hline Digital resolution & 12 bit \\
\hline Communication & SPI \\
\hline Mass & $20[\mathrm{~g}]$ \\
\hline
\end{tabular}

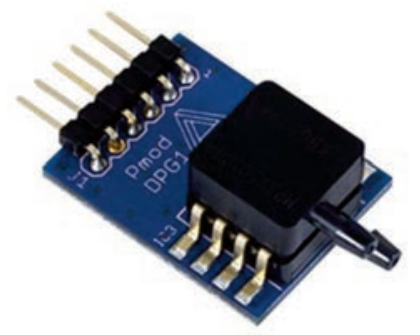

Figure 5. PMOD DPG1 Differential pressure sensor.

- HX711 - Load Cell Amplifier can be used for strain gauge measurements e.g. forces, strain, deformations etc.

Table 4. HX711 Basic data.

\begin{tabular}{|c|c|}
\hline Parameter & Value \\
\hline Gain & 64 or 128 \\
\hline Digital resolution & 24 bit \\
\hline Sampling rate & $80[\mathrm{~Hz}]$ \\
\hline Communication & Own protocol \\
\hline Mass & $5[\mathrm{~g}]$ \\
\hline
\end{tabular}

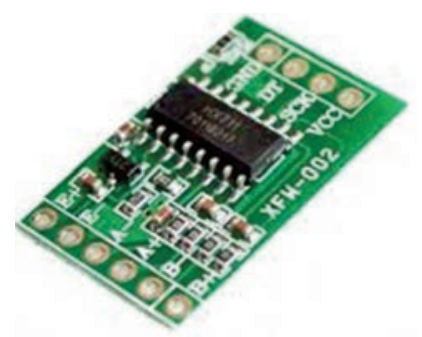

Figure 6. HX711 Load Cell Amplifier.

LabVIEW (Laboratory Virtual Instrument Engineering Workbench) is a systemdesign platform from National Instruments (NI) which uses the visual programming language "G". LabVIEW was designed especially for data acquisition and analysis, instruments control and industrial automation.

The traditional text-based programming language was replaced by a graphical bloc diagram (which is used in the same manner as a programming command). The user design front panel from a virtual instrument and the block diagram from a virtual instrument are shown below. 


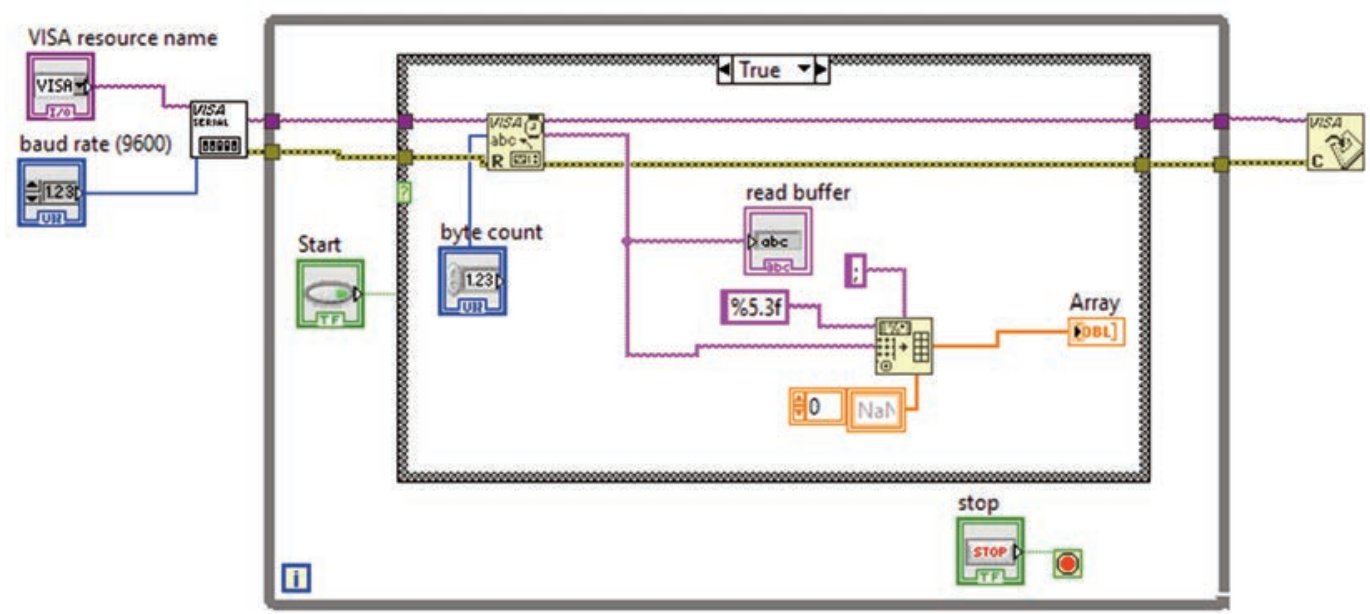

Figure 7. LabVIEW example code.

In terms of data acquisition, the most difficult to perform are helicopter flight tests. The most interesting investigations from a designer's or flight test engineer's point of view are measurements performed on helicopter rotor blades. In this case it is very difficult to transmit signals from rotating parts of a helicopter. Engineers drill a tunnel in the main shaft or use a commutator. These techniques require helicopter modifications (as a result of which the helicopter can only be used for tests and another stress calculation has to be performed). Another possibility for signal transmission is to use WiFi or other wireless transmission.

The most important elements of a helicopter flight test are vibration and cyclic loads measurements. These data are necessary for fatigue calculations, which are an essential part of the helicopter design (predictions of a helicopter's life limit).

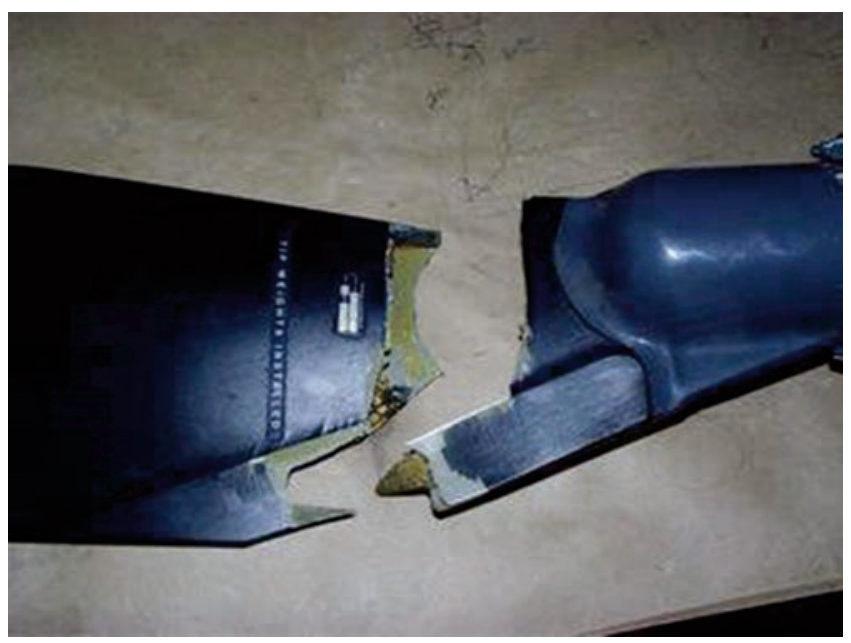

Figure 8. Robinson helicopter series main rotor blade crack caused by a fatigue process.

Using the Arduino platform with an embedded WiFi module makes it possible to send data from the main rotor hub / blades to a computer located on helicopter board 
without any wires and construction modifications. This is the costless and the fastest way to get data from the helicopter main / tail rotor.

Data acquisition unit tests are performed on Robinson R44 helicopters.

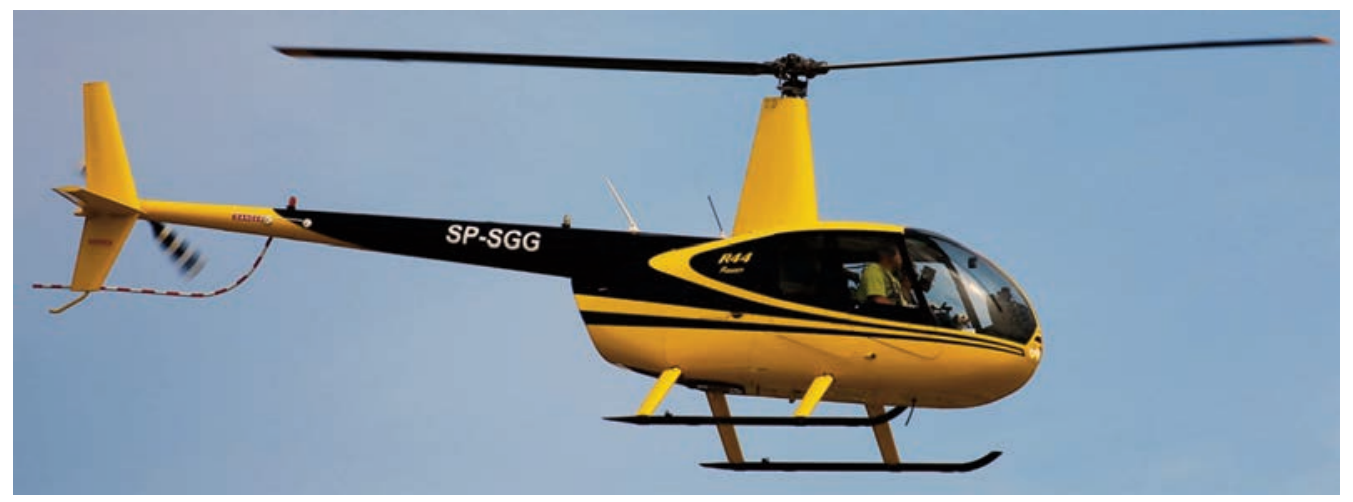

Figure 9. Helicopter used in flight tests (internet source).

\section{OBJECTIVE OF THE RESEARCH STUDY}

The objective of the research study was to enable the use of the Arduino platform integrated with LabVIEW for flight test data acquisition.

\section{SYSTEM INTEGRATIONS}

The Arduino platform is equipped with many communication ports and an analogto-digital converter.

The most common communication protocols used to communicate with other sensors and devices are $\mathrm{I}^{2} \mathrm{C}$ and SPI protocol and UART used specifically for transmission between Arduino and a PC.

The disadvantage of the $\mathrm{I}^{2} \mathrm{C}$ and SPI protocols is that communication is possible only at short distances (not more than 1 meter). Above 1 meter, communication becomes unstable and interfered by noise. This distance is too short for test flight use (even for very small aircraft).

The solution to this problem is to use MAX491 low-power transceivers which convert $\mathrm{I}^{2} \mathrm{C}$ and SPI protocols to RS485 (maximum distance for this protocol is $1200 \mathrm{~m}$ ). The disadvantage of this solution is that the signal has to be converted again before it reaches Arduino.
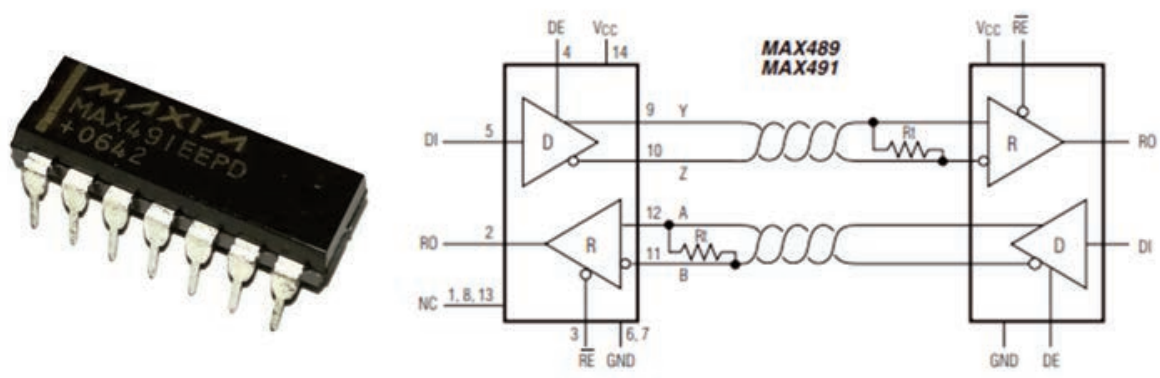

Figure 10. MAX491 Module for protocol conversion. 
The Arduino programming language is a modified $\mathrm{C}++$ language with additional commands for microprocessor and platform controlling. Microprocessor programing is performed from a PC level by a special dedicated software, Arduino IDE. The software is equipped with a debugger and loading the programing code is done by a USB wire.

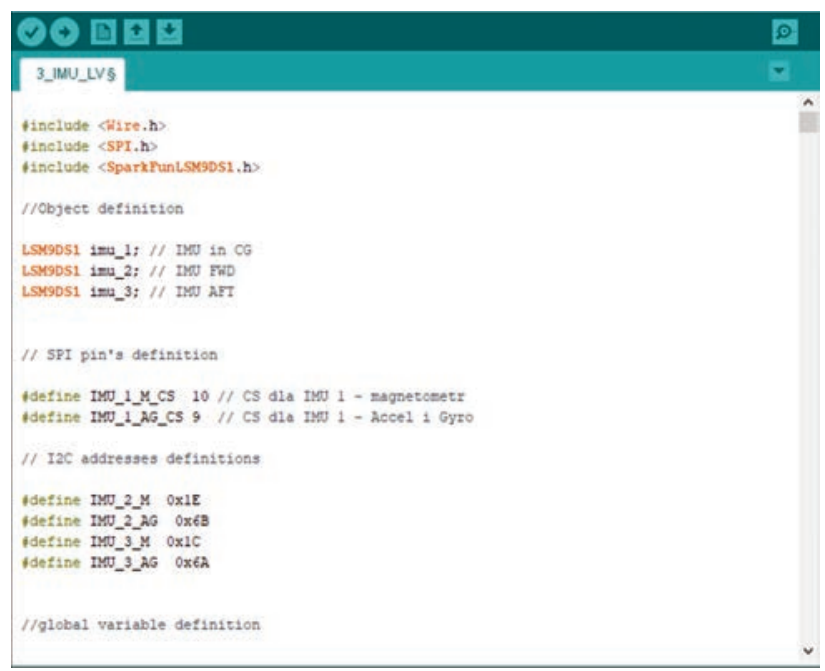

Figure 11. Example of Arduino code for three IMUs use.

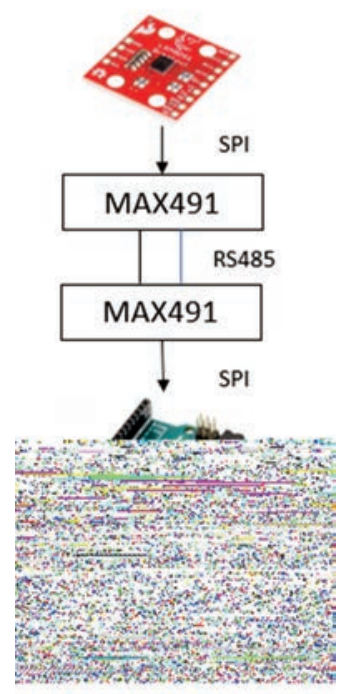

Figure 12. Data acquisition unit block diagram.

The data from Arduino are transmitted via UART (using a USB port) to the PC. UART protocol has a limitation of $115200 \mathrm{bit} / \mathrm{s}$ for transmitting data. The solution could be to use Ethernet protocol which allows transmitting data at $100 \mathrm{Mbit} / \mathrm{s}$. 
The data are then read by LabVIEW with the use of a special software package NI VISA (dedicated to reading data from a serial port) after reading, the data are saved to file.

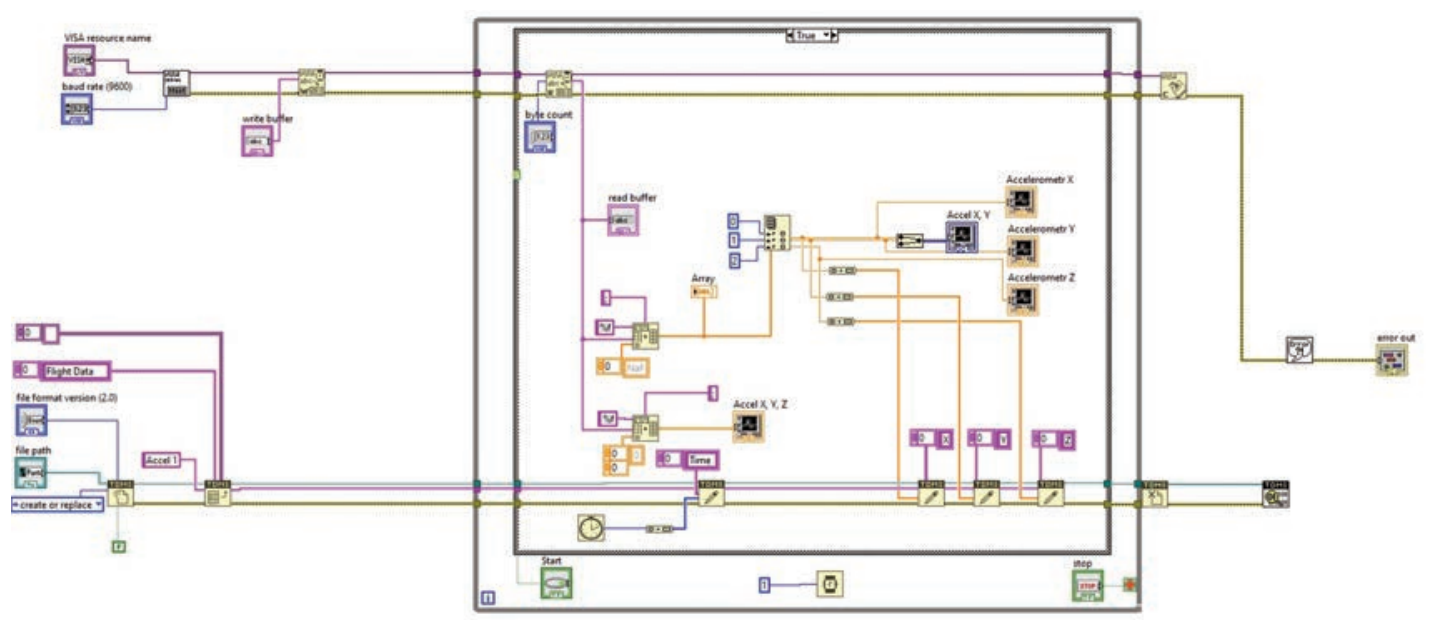

Figure 13. LabVIEW block diagram for 2-axis accelerometer data acquisition.

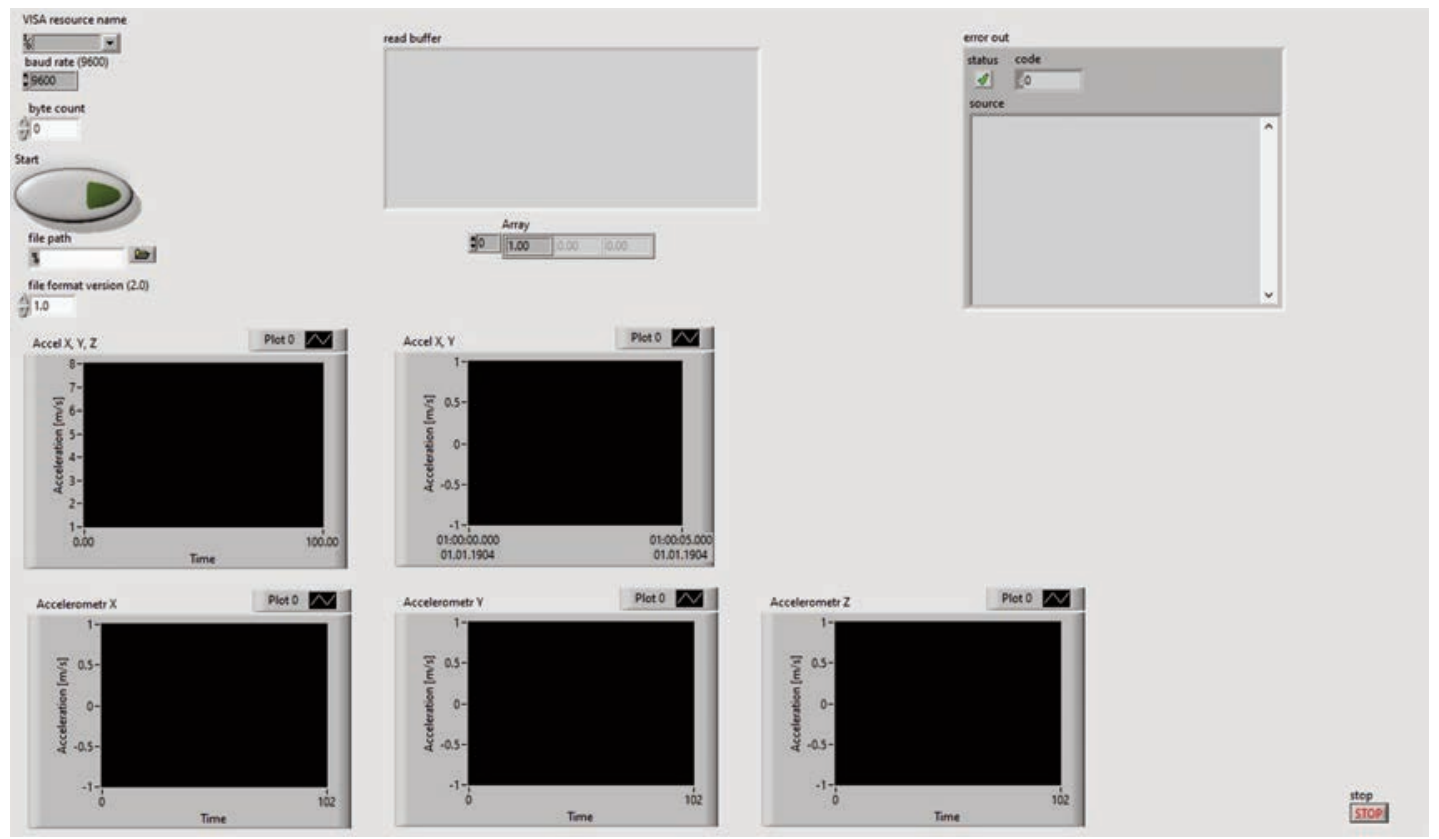

Figure 14. LabVIEW virtual instrument (front panel).

National Instruments has created special, dedicated file formats (TDM or TMDS) for data acquisition with a very high saving speed.

TDM / TDMS file contains three levels of data. The First Data Set (root) with all file descriptions, the second level is a group of channels and the third one is channels. The number of groups and channels is unlimited (limited only by disk space). 


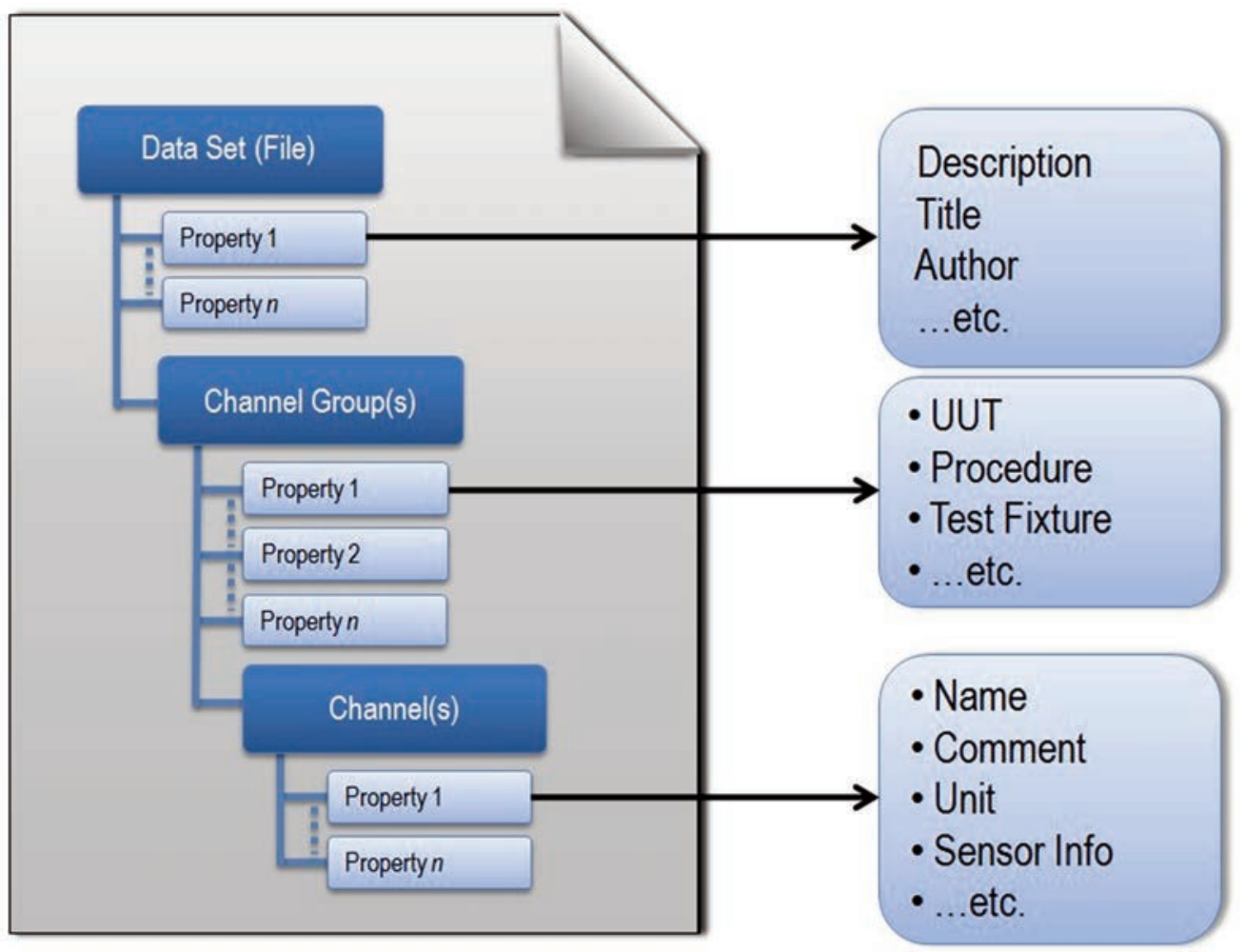

Figure 15. TDMS file structure.

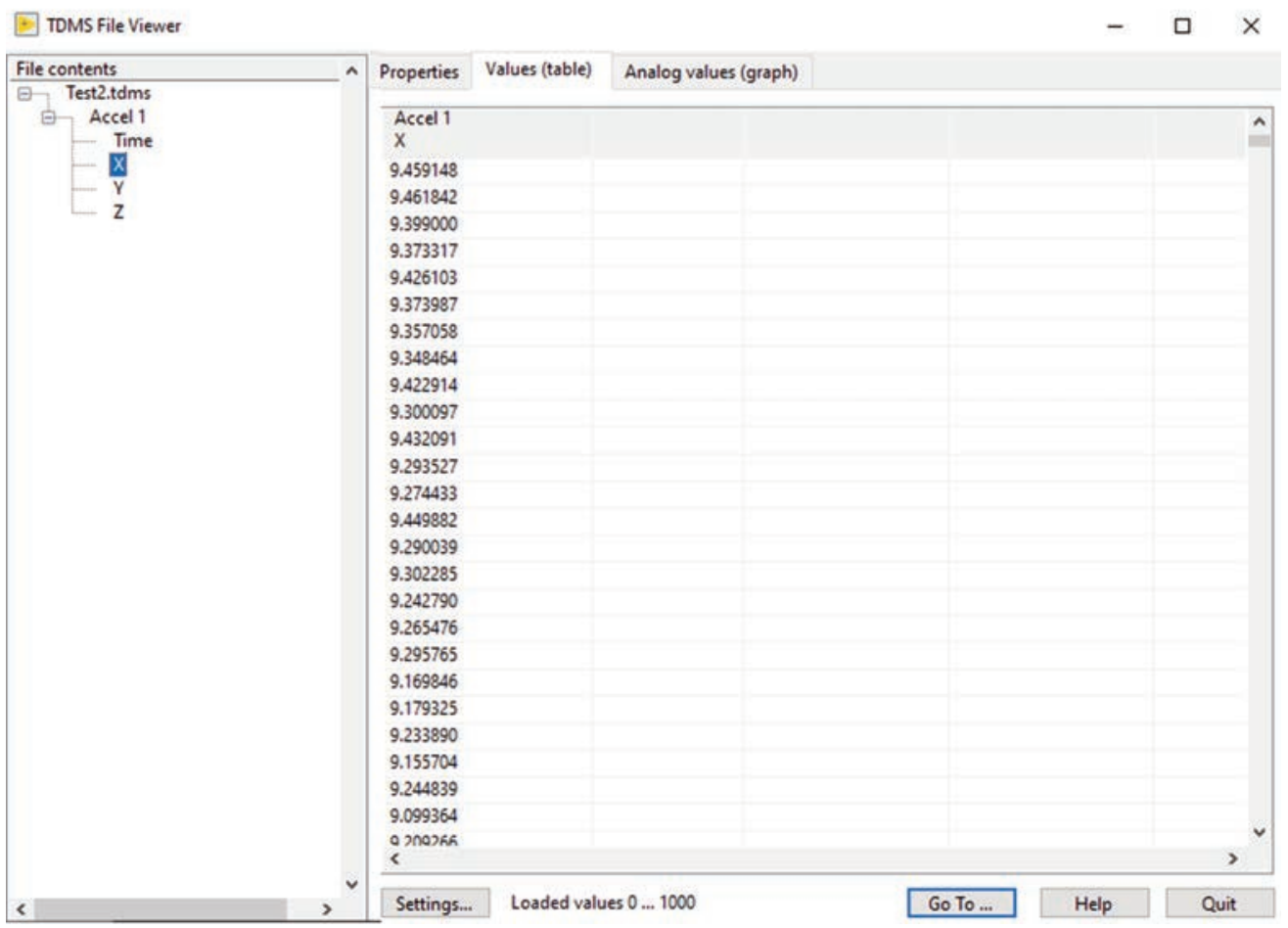

Figure 16. Standard Gravity acceleration measurement (TDMS File Viewer). 
TDMS file enables data acquisition at a very high saving speed. Special software ensures a fast data analysis.

Data from TDMS files are analyzed by a special software package to LabVIEW or a special dedicated software e.g. DIAdem developed by National Instruments. The data from TDMS files can be divided and exported to an Excel spreadsheet file or analyzed directly with the software mentioned above.

\section{CONCLUSIONS}

The low-cost data acquisition unit design method presented in this article can find application in the small aviation industry. The biggest advantage is the low price of components and their availability.

The biggest problem is the access to LabVIEW software but it can be superseded by an SD card reader.

Most worktime is changing Arduino and LabVIEW programing code every time when we change configuration of data acquisition unit.

Another problem is access to a sensor with sampling rate above $1 \mathrm{kHz}$ but on the other hand the sensors are accurate enough to perform flight test measurements for gliders and small airplanes.

Sensors setup above the distance of 1 meter requires adding another signal convertor which increases the complexity of equipment and the possibility of failure.

\section{REFERENCES}

[1] Anderson, R. and Cervo, D. (2014). "Arduino dla Zaawansowanych". Warsaw: Helion. ISBN: 978-83-246-8222-5.

[2] National Instruments, "LabVIEW User Manual” April 2013.

[3] Rodzewicz, M. and Leszczynski, P. (2012). "Metodyka pomiarow i rejestracji obciazen w locie statku powietrznego o konstrukcji kompozytowej”, Biuletyn WAT, Vol. LXI, No. 3.(in Polish)

[4] Pool, D. and Bosman, A., (1989). "AGARD Flight Test Instrumentation Series, Volume I”, AGARD-AG-160 vol. 1. 